\title{
Anaesthesia for paediatric emergency in a very sick child in a low resource setting: A case report
}

\author{
Yvonne Omieipirisa Buowari* \\ Department Of Anaesthesiology, University Of Port Harcourt Teaching Hospital, Port Harcourt, Rivers State, Nigeria
}

\begin{abstract}
Background: Paediatric emergency requires special training especially when it involves anaesthesia. Patients present late to health facilities especially in countries where drugs can be purchased over the counter. Very ill children requiring emergency surgery require special attention because there may be electrolyte derangement.

Case summary: A six year old was referred to the emergency room of a tertiary health facility from a private hospital with complaints of vomiting, constipation, fever, abdominal distension and abdominal pain. The patient was clinically ill looking, pale; generalised abdominal pain, tenderness and distension. Serum electrolytes were deranged. General anaesthesia was administered for emergency laparotomy. Anaesthesia was induced with halothane, maintained with halothane, oxygen and pentazocine. Surgical findings were intestinal perforation and resection was done. The patient recovered and the postoperative period was uneventful.
\end{abstract}

Conclusion: There is need for emergency anaesthetic services in developing and low income countries. There is need for continuous training in the administration of emergency anaesthesia to help reduce child morbidity and mortality from surgical emergency and availability of blood bank services and antibiotics.

\section{Introduction}

The acute abdomen is a term used to encompass a spectrum of surgical, medical and gynaecological conditions ranging from trivial to the life threatening which require hospital admission, investigation and treatment [1]. It is of sudden onset that may require immediate operative treatment caused by inflammatory conditions, perforation, colics, gynaecological and medical conditions [2]. Emergency surgery usually refers to surgery occurring within 24 hours of admission or diagnosis that is includes those cases whose surgery resuscitation and those whose surgery and resuscitation proceed simultaneously [3]. Some of the problems may be related to inadequate preparation of patients for surgery, full stomach that is risk of aspiration of gastric contents, electrolyte imbalance, appropriate imbalance, appropriate investigations and cross matching of blood may not be performed or not ready, haemorrhage and hypovolaemia, dehydration and further risk of aspiration due to delayed gastric emptying and hypovolaemia ${ }^{3}$. For emergency surgery compromises may have to be made for some aspects of preoperative preparation and balanced against the risks of delayed surgery [4].

\section{Case summary}

A six year old boy was referred from a private clinic with complaints of abdominal swelling, abdominal pain and fever of one week duration and vomiting of five days duration and black tarry stools. The abdominal swelling was generalised. Abdominal pain at the onset was at the lower abdomen and of sudden onset and progressively became. Constipation was noticed the day abdominal distension started. Vomitus initially consisted of recently ingested feeds and later consisted of clear fluids when patient could not eat. There was difficulty in breathing as the abdomen continued to distend. Fever was higher grade and continuous.

At the onset of the illness, the patient was given some unknown drugs bought over the counter a patent medicine dealer shop and was given some herbal concoctions by the aunty. There was no improvement hence he was taken to a private clinic that referred the patient to the children emergency room of a Nigerian teaching hospital. On examination, the child was clinically ill looking, wasted with prominent ribs and zymotic arch, in respiratory distress evidenced by flaring alae nasi, subcostal and intercostal recession, in obvious painful distress, dehydrated evidenced by sunken eye balls dry buccal mucosa. $\mathrm{He}$ was immediately placed on oxygen by nasal prongs. Nasogastric tube was insitu draining brown coloured bolus fluid, weight $14 \mathrm{~kg}$, febrile temperature $38.6^{\circ} \mathrm{C}$, pale ++ , pulse rate 178 beats per minute, low volume and thread, respiratory rate 53 cycles per minute, chest auscultation was resonant breath sounds with reduced air entry on the left lung field, heart rate 156 beats per minute, heart sounds one and two was heard. The abdomen was uniformly enlarged, moves with respiratory with dilated umbilical vein, everted umbilicus, generalised tenderness, abdominal gait $40 \mathrm{~cm}$. abdominal organs could not be palpated as a result of gross distension, fluid thrill was positive and bowel sounds absent. Rectal examination findings are poor anal hygiene, intact anal sphincter, tender and empty rectum, examining finger was stained with dark stool. Temperomandibular joint was mobile with malampathi I. A diagnosis of acute abdomen was made packed cell volume was $25 \%$. Abdominal ultrasounds scan showed bowel wall thickness measuring about $6 \mathrm{~mm}$ with bowel dilatation and slow peristalsis. Abdominal $\mathrm{x}$-ray showed free peritoneal fluid, pneumoperitoneum and floating

Correspondence to: Dr. Yvonne Omiepirisa Buowari, Department of Anaesthesiology, University of Port Harcourt Teaching Hospital, Port Harcourt, Rivers State, Nigeria; E-mail: dabotabuowari@yahoo.com

Key words: acute abdomen, anaesthesia, morbidity, emergency surgery

Received: August 08, 2016; Accepted: September 04, 2016; Published: September 09, 2016 
dilated bowel. Nasogastric tube drain reservoir drained $1.2 \mathrm{~L}$ of pussy peritoneal fluid. Result of serum sodium $145 \mathrm{mmol} / \mathrm{l}$, serum potassium $3.5 \mathrm{mmol} / \mathrm{l}$, serum bicarbonate $22 \mathrm{mmol} / \mathrm{l}$, and serum urea $4.3 \mathrm{mmol} / \mathrm{l}$. The patient was placed on full strength dextrose to alternate with $4.3 \%$ dextrose in one fifth saline, intravenous antibiotics, nil per oral and arrangements made for emergency exploratory laparotomy. Patient was assessed as American Association of Anaesthesiologists (ASA) IV ${ }^{\mathrm{E}}$. Premedication of glycopyrolate was given, baseline vital signs recorded preoxygenetaion with $100 \% 4 \mathrm{l}$ fractional oxygen. Anaesthesia was induced with halothane and maintained with halothane, oxygen and pentazocine. Anaesthesia was monitored with pulse oximeter, blood loss, respiratory rate, precordial stethoscope and urine output.

Surgical findings were necrosis of the distal ileum extending to the caecum with the appendix buried in the inflammation, massive feculent exudate, fibrinous exudate, and multiple paracolic lymphadenopathies. Faecal effluent of $1.8 \mathrm{~L}$ was suctioned. Left hemicolectomy was done with ileocolic anastomosis. The peritoneum was irrigated and drain left in position. Blood loss was $400 \mathrm{mls}$. Patient received blood transfusion in the course of surgery. Anaesthesia was reversed by putting dialling off halothane and received oxygen by facemask initially and later by intranasal prongs for the next 24 hours. Postoperative packed cell volume was $23 \%$. Intravenous analgesic, antibiotics and fluids was continued until bowel sounds returned. The patient was discharged home on the tenth postoperative day in good condition on oral haematinics, analgesics, antibiotics and high protein diet.

\section{Discussion}

The health seeking behaviour in developing countries including Nigeria is poor as everyone seems to have knowledge about illness because when complaints are made that even the layman prescribes drugs he does not know anything about the its pharmacology. In Nigeria though the authorities in charge have tried to stop it, drugs can be bought over the counter from patent medicine dealers without doctor's prescription. Drugs can also be purchased from drug vendors who parade the streets without any licenced to dispense drugs. The patient was a minor and therefore cannot make decisions for himself. His parents did not consult a medical doctor at the onset of the illness; it may not have progressed ASA IV ${ }^{\mathrm{E}}$. It has been estimated that at least $50 \%$ of general surgery admissions are emergencies and of these $50 \%$ present with acute abdominal pain [1]. There are four cardinal features of acute intestinal obstruction are pain, vomiting, distension and constipation [1-2,5]. Which was present in the patient late manifestations which may be encountered included dehydrated, oliguria, hypovolaemia, shock, pyrexia, septisaemia, respiratory embarrassment and peritonitis [5]. Abdominal pain is the primary and first symptom and occurs suddenly and is usually severe and bowel sounds are absent $[1,5]$. Dehydration is seen moat commonly in small bowel obstruction due to repeated vomiting and fluid sequestration. This results in dry skin and tongue, poor venous filling and sunken eyes with oliguria. The blood urea level and haematocrit rise give a secondary polycythaemia [5]. This patient was dehydrated, ill looking, in respiratory and painful distress and septisaemia. Pyrexia is the presence of obstruction may include the onset of ischaemia, intestinal perforation, inflammation associated in the obstructing disease. The development of peritonism or peritonitis indicates overt infarction and /or perforation [5]. Typhoid perforation is a cause of visceral perforation. In acute obstruction, gas and intestinal secretions accumulation causing distension of the gastrointestinal tract proximal to the obstruction resulting in pain, increased bowel activity and vomiting [3]. Therefore dehydration and electrolyte disturbances may develop. If severe and unrelieved obstruction may lead to bowel ischaemia, necrosis and perforations [3] as seen in this patient. Abdominal x-ray may reveal dilated loops of bowels with fluid levels [3]. There are three main measures of treatment for acute intestinal obstruction which are gastrointestinal tract drainage, fluid and electrolyte correction and relief of the obstruction which is usually surgical [5]. Surgical treatment is necessary for most cases of intestinal obstruction [5]. This patient had electrolyte derangement but the patient had to be operated because the prognosis was poor even if surgery was withheld. Resuscitation went on even till surgery; the gut was decompressed by the passage of nasogastric tube. Emergency surgery and anaesthesia was vital through the patient was not medically fit. That is why muscle relaxants were not used and minimal drugs used to worsen the patient's condition. Hypovolaemia produces cardiac arrhythmias, impairs cardiac contractility, renders the muscles weak and sensitive to muscle relaxants [6]. The main difference between emergency and elective surgery is that there is little time for investigation and less information may be available. Patients' requiring emergency surgery may be very sick and may require basic resuscitation prior to anaesthesia and surgery [4]. The patient with acute abdominal pain has a significant morbidity and mortality [1]. Spontaneous perforation of an intra-abdominal viscous may be the result of a range of pathological process. Weakening of the wall of the viscous which may follow degeneration, inflammation, infection or ischaemic which will predispose to perforation. Spontaneous perforation of a viscous usually results in the sudden onset of severe abdominal pain. The inevitable peritoneal contamination will lead to peritonitis [1] as seen in this patient. Suxamethonium was not administered to facilitate intubation. Children are more susceptible than adults to cardiac arrhythmias, rhabdomyomitis, myoglobinaemia, masseter spasm and malignant hyperthermia after administration of succinylcholine. For this reason succinylcholine is best avoided for routine surgery in children [7]. The objective of modern anaesthesia is to rapidly obtain a state of unconsciousness, to maintain this state and then achieve a rapid recovery. An important advantage of the inhalational route over the intravenous route is the maintenance of airway control, respiration is maintained, slow loss of protective reflexes, and rapid recovery of induction is abandoned [8]. The patient was not fit for anaesthesia, resuscitation was on going, and electrolytes were deranged therefore only analgesia and inhalational anaesthesia was used. Halothane was the only inhalational anaesthetic agent present at the centre when the patient presented.

\section{Conclusion}

Emergency surgery and anaesthesia is challenging in developing and low resource countries where minimal equipment is available. Children are subjected to different forms of treatment especially in developing countries like Nigeria where most patient prefer home treatment and only present late in health facilities when the illness have progressed to complicated cases. Paediatric anaesthesia is a delicate type of anaesthesia because children are not small adults and need to be handled with care. A patient with ASA IV ${ }^{\mathrm{E}}$ is critical cases and takes careful management to in developing countries.

\section{References}

1. Smith GCS, Paterson-Brown S (2007) The acute abdomen and intestinal obstruction In. Garden OJ, Bradbury AW, Forsythe J. Principles and practice of surgery. Elsevier Churchill Livingstone. Fourth edition. China. 198-220.

2. Naaeder SB. Acute abdomen. In. Badoe EA, Archampong EQ, da Rocha-Afodu JT (2000) Principles and practice of surgery including pathology in the tropics. Third Edition. University of Ghana Medical School. Third Edition. Accra. 503-508.

3. Yentis S, Hirsch N, Smith G (2009) Anaesthesia and Intensive Care A-Z. Fourth 
Edition. Churchill Livingstone Elsevier. Edinburgh. 188-289.

4. Walsh TS, Pollok AJ (2007) Preoperative assessment and investigations. In. Garden JO, Bradbury AW, Forsythe J. (Eds). Principles and practice of surgery. Fourth edition. Elsevier Churchill Livingstone. China. 106-123.

5. Winslet MC (2000) Intestinal Obstruction. In. Russell RCG, Williams NS, Bulstrode CJR. Bailey and Love's Short Practice of Surgery. Twenty Third. Edition. Arnold. London. 1060-1075.
6. Duke J (2009) Electrolytes. In. Duke J. (Ed). Anaesthesia Secrets. Third Edition. Elsevier. India. 34-38.

7. Morgan E, Mikhail MS (2006) Clinical Anaesthesiology. McGraw-Hill Medical Books. New York. 931-938.

8. Parr SM (2003) Induction of anaesthesia. In. Pinnock C, Lin T, Smith T. Fundamentals of anaesthesia. Second Edition. Greenwich medical media. England. 27-42.

Copyright: $\odot 2016$ Buowari YO. This is an open-access article distributed under the terms of the Creative Commons Attribution License, which permits unrestricted use, distribution, and reproduction in any medium, provided the original author and source are credited. 